\title{
First Principles Investigation of Half-Metallic Ferromagnetism in Alkaline-Earth Oxides Doped with Group VII Elements
}

\author{
M. Yogeswari ${ }^{1 *}$ and G. Kalpana ${ }^{2}$ \\ 'Department of Physics, Vellalar College for Women, Thindal, Erode - 638012, Tamil Nadu, India \\ 2Department of Physics, College of Engineering, Guindy Campus, Anna University, Chennai -_600025, \\ Tamil Nadu, India
}

\begin{abstract}
Alkaline-earth oxides (AeO; $\mathrm{Ae}=\mathrm{Mg}$, $\mathrm{Ca}$ and $\mathrm{Sr}$ ) doped with group VII (F, Cl, Br and I) elements as promising spin-injector materials have been investigated by using first principles full-potential linearized augmented plane-wave method. The substitution of group VII elements turns the insulator host $\mathrm{AeO}$ into ferromagnetic and some of them exhibit half-metallic ferromagnetic property with an integer magnetic moment of $3.00 \mu_{B}$ /cell. The spin-resolved electronic band structure and density of states show that the $\mathrm{Ae}_{0.875} \mathrm{M}_{0.125} \mathrm{O}$ compounds exhibit spin-dependent transport properties, in which the conduction proceeds entirely via the minority spin state in $\mathrm{F}$-doped $\mathrm{AeO}$ and through majority spin state in $\mathrm{Cl}$, $\mathrm{Br}$ and I-doped $\mathrm{CaO}$ and $\mathrm{SrO}$. The comparison of local spin density approximation and generalized gradient approximation is also carried out. The results show that the origin of ferromagnetism in $\mathrm{Ae}_{0.875} \mathrm{M}_{0.125} \mathrm{O}$ is attributed to the $p-p$ hybridization interaction between group VII elements and oxygen.
\end{abstract}

Keywords: Alkaline-Earth Oxides, First Principles Calculation, Half-Metallic Ferromagnet, Non-Magnetic Impurity

\section{Introduction}

Half-Metallic (HM) ferromagnetism have became a fascinating material because of their plausible application in the field of spintronics. HM ferromagnets possess metallic behavior in one spin channel and insulator/semiconducting behavior in another spin channel. This leads to $100 \%$ spin polarization around the Fermi energy level. Since de Groot et al explored the HM ferromagnetism in NiMnSb (R.A. de Groot, 1983) [1] by means of first principles application, a number of HM ferromagnets have been theoretically predicted and many of them have been confirmed experimentally (Y.H. Zhao, 2006) [2].

Recently, theoretical calculations of $\mathrm{CaO}(\mathrm{K}$. Kenmochi, 2004) [3] doped with nonmagnetic elements $(\mathrm{B}, \mathrm{C}$ and $\mathrm{N})$ at the anion site showed that $\mathrm{C}$ and $\mathrm{N}$-doping results in half-metallicity, but B-doping does not induce any magnetic moment. Moreover, half-metal- lic ferromagnetism in $\mathrm{AeO}$ (K. Kenmochi, 2004) [4] and $\mathrm{BeO}$ (I.R. Shein, 2012) [5] with the incorporation of B, C and $\mathrm{N}$ have been substantially investigated by first-principles calculations. Based on density functional theory, Liu et al., (J. Liu, 2009) [6] have reported that the C-doping in alkaline-earth oxides and sulfides induce HM ferromagnetism. These types of ferromagnetic materials challenge our understanding of origin of ferromagnetism. Halfmetallic ferromagnetism in $\mathrm{M}_{2} \mathrm{O}(\mathrm{M}=\mathrm{Li}, \mathrm{Na}, \mathrm{K}$ and $\mathrm{Rb})$ in the presence group VI elements was reported (R.D. Eithiraj, 2012) [25].

In this work, the spin-dependent electronic band structure calculations of the $\mathrm{Ae}_{0.875} \mathrm{M}_{0.125} \mathrm{O}$ ( $\mathrm{Ae}=\mathrm{Mg}$, Ca and $\mathrm{Sr} ; \mathrm{M}=\mathrm{F}, \mathrm{Cl}, \mathrm{Br}$ and I) in the NaCl-type structure have been studied systematically. Both non spin-polarized and spin-polarized calculations have been carried out for each compound to find the possibility of existence of ferromagnetism and half-metallic property. The

${ }^{*}$ Author for correspondence 
influence of different exchange-correlation (xc) functions namely Local Spin Density Approximation (LSDA) and Generalized Gradient Approximation (GGA) on the electronic structure and half-metallic property of the doped $\mathrm{AeO}$ compounds have been analyzed. To the best of our knowledge, the ferromagnetism and half-metallic property in $\mathrm{Ae}_{0.875} \mathrm{M}_{0.125} \mathrm{O}$ compounds are not predicted so far. In addition, the band structures and density of states for the titled compounds are plotted.

\section{Computational Details}

In the present calculations, the geometry optimization and the electronic structure of $\mathrm{Ae}_{0.875} \mathrm{M}_{0.125} \mathrm{O}$ in the NaCltype structure are performed using all-electron FP-LAPW method implemented in WIEN2k code (P. Blaha, 1990) [7]. Both LSDA with the reparameterization of CeperleyAlder data (D.M. Ceperley, 1980) [8] and GGA (J.P. Perdew, 1996) [9] proposed by Perdew-Brouke-Ernzerhof are used for $\mathrm{xc}$ potential. It has been done in order to find out the dependence of the structural and magnetic properties on the $\mathrm{xc}$ potential. The scalar relativistic treatment is used for the valence states, whereas the core ones are treated fully relativistically (D.D. Koelling, 1977) [10]. In order to achieve energy eigenvalue convergence, the wave functions in the interstitial region are expanded in plane waves with a cutoff of $\mathrm{K}_{\max }=8 / \mathrm{R}_{\mathrm{MT}}$ (where $\mathrm{K}_{\max }$ is the maximum value of the wave vector $\mathrm{K}=\mathrm{k}+\mathrm{G}$ and $\mathrm{R}_{\mathrm{MT}}$ is the average radius of the muffin-tin spheres). The muffin-tin sphere radii are $\mathrm{R}_{\mathrm{MT}}=1.7$ a.u. for $\mathrm{F}, 2.0$ a.u. for $\mathrm{Mg}, \mathrm{Ca}, \mathrm{O}$ and $\mathrm{Cl}, 2.3$ a.u. for $\mathrm{Br}$ and $\mathrm{Sr}$ and $2.5 \mathrm{a}$ a. for I. Atomic orbitals upto an angular momentum $l_{\max }=10$ are used to expand the wave functions inside muffin-tin spheres. Thus, in order to keep the same degree of convergence for all the lattice constants studied, the values of the sphere radii and $\mathrm{K}_{\max }$ are kept constant over all the range of lattice spacing considered. The integration in reciprocal lattice space is performed using the modified tetrahedron method (P.E. Blöchl, 1994) [11]. The band structure and density of states are calculated using $8 \times 8 \times 8$ mesh ( $600 \mathbf{k}$-points) in the first Brillouin zone. The self-consistency is considered to be achieved when the integrated charge density per formula unit, between the input charge density and the output charge density is less than 0.0001 e/a.u [3].

To study the doping effect in $\mathrm{AeO}$ host compounds, supercell containing 16 atoms is constructed. The replacement of one sulfur atom by one dopant atom in the supercell represents 12.5\% doping (M. Yogeswari, 2012).

\section{Results and Discussion}

\subsection{Structural Properties and Stability}

The total energy calculations of the binary host compounds $\mathrm{AeO}(\mathrm{Ae}=\mathrm{Mg}, \mathrm{Ca}$ and $\mathrm{Sr})$ are performed within LSDA and GGA in order to calculate the equilibrium lattice constant $\left(a_{0}\right)$ and bulk modulus $\left(\mathrm{B}_{0}\right)$. The calculated lattice parameters and bulk modulus are tabulated in Table 1, and they are in good agreement with previously reported results (Y. Fei, 1999) [13], (S. Speziale, 2001) [14], (T. Tsuchiya, 2001) [15], (J.E. Jaffe, 2000) [16]. As compared to the experimental value, the lattice constants are underestimated within LSDA and overestimated within GGA (M. Yogeswari, 2013) [26].

For calculating the electronic and magnetic properties of $\mathrm{Ae}_{0.875} \mathrm{M}_{0.125} \mathrm{O}(\mathrm{Ae}=\mathrm{Mg}$, Ca and $\mathrm{Sr} ; \mathrm{M}=\mathrm{F}, \mathrm{Cl}, \mathrm{Br}$ and I $)$, geometry optimization is performed. Spin-polarized calculations reveal that incorporation of group VII elements as dopants in $\mathrm{AeO}$ hosts, turn most of host compounds into ferromagnetic semiconductors. In order to calculate the equilibrium lattice constant and bulk modulus for the given stoichiometry, the total energies are calculated for $\mathrm{Ae}_{0.875} \mathrm{M}_{0.125} \mathrm{O}$ compounds in both ferromagnetic (FM) and nonmagnetic (NM) states. The calculated total energies as a function of reduced volume are fitted to Birch-Murnaghan equation of state (Birch, 1947) [17]. The calculated equilibrium lattice constant and bulk modulus obtained using LSDA and GGA are given in Table 1. From Table 1, it can be seen that the equilibrium lattice constant of doped system is larger within GGA and smaller within LSDA compared to the equilibrium lattice constant of AeO. As mentioned earlier, GGA overestimates and LSDA underestimates the lattice constant. The lattice constant of the doped system increases as the size of the dopant increases. Since the unit cell expands more to accommodate the bigger dopant atom.

Bulk modulus is a scalar quantity relating the isotropic pressure to the average change in volume. It is determined entirely by the resistance of the outermost, or valence electrons to compression. From the calculated bulk modulus (Table 1), it can be seen that mechanical stability of the doped system decreases along the sequence of $\mathrm{F}, \mathrm{Cl}, \mathrm{Br}$ and I. This indicates that the atomic size of the dopant play an important role in determining the ground state properties of the title compounds. These results enumerate the general trend when compared with the two different $\mathrm{xc}$ approaches; GGA yields larger lattice parameter and smaller bulk modulus compared to LSDA. 
Table 1. Calculated equilibrium lattice constant $\left(a_{0}\right)$ and bulk modulus $\left(b_{0}\right)$ for both nonmagnetic $(N M)$ and ferromagnetic (FM) states of $\mathrm{Ae}_{0.875} \mathrm{M}_{0.125} \mathrm{O}(\mathrm{Ae}=\mathrm{Mg}$, $\mathrm{Ca}$ and $\mathrm{Sr} ; \mathrm{M}=\mathrm{F}, \mathrm{Cl}, \mathrm{Br}$ and I) using both LSDA and GGA

\begin{tabular}{|c|c|c|c|c|c|c|c|c|c|c|}
\hline \multirow{4}{*}{ Compounds } & \multicolumn{5}{|c|}{$a_{0} \AA$} & \multicolumn{5}{|c|}{$\mathrm{B}_{0} \mathrm{GPa}$} \\
\hline & \multicolumn{4}{|c|}{ Present } & \multirow{3}{*}{ Exp. } & \multicolumn{4}{|c|}{ Present } & \multirow{3}{*}{ Exp. } \\
\hline & \multicolumn{2}{|c|}{ LSDA } & \multicolumn{2}{|c|}{ GGA } & & \multicolumn{2}{|c|}{ LSDA } & \multicolumn{2}{|c|}{ GGA } & \\
\hline & NM & FM & NM & FM & & NM & FM & NM & FM & \\
\hline Present & 4.168 & & 4.260 & & $\begin{array}{l}4.213^{\mathrm{a}} \\
4.212^{\mathrm{b}} \\
\end{array}$ & 174.6 & & 146.3 & & $156^{\mathrm{d}}$ \\
\hline Others & $\begin{array}{l}4.168^{\mathrm{c}} \\
4.167^{\mathrm{e}}\end{array}$ & & $\begin{array}{c}4.260^{\mathrm{c}} \\
4.25^{\mathrm{f}}\end{array}$ & & & $\begin{array}{c}173.4^{\mathrm{c}} \\
172^{\mathrm{e}}\end{array}$ & & $\begin{array}{l}154.2^{\mathrm{c}} \\
159.7^{\mathrm{f}}\end{array}$ & & \\
\hline $\mathrm{Mg}_{0.875} \mathrm{~F}_{0.125} \mathrm{O}$ & 4.191 & 4.192 & 4.291 & 4.293 & & 161.6 & 160.3 & 135.5 & 134.2 & \\
\hline $\mathrm{Mg}_{0.875} \mathrm{Cl}_{0.125} \mathrm{O}$ & 4.280 & 4.281 & 4.374 & 4.376 & & 157.4 & 157.1 & 132.1 & 131.3 & \\
\hline $\mathrm{Mg}_{0.875} \mathrm{Br}_{0.125} \mathrm{O}$ & 4.333 & 4.335 & 4.428 & 4.430 & & 154.9 & 130.2 & 129.9 & 129.1 & \\
\hline $\mathrm{Mg}_{0.875} \mathrm{I}_{0.125} \mathrm{O}$ & 4.421 & 4.425 & 4.524 & 4.524 & & 145.8 & 144.0 & 126.0 & 126.7 & \\
\hline Present & 4.718 & & 4.839 & & $4.810^{\mathrm{g}}$ & 130.7 & & 106.2 & & $110^{\mathrm{g}}$ \\
\hline Others & $4.71^{\mathrm{e}}$ & & $4.86^{\mathrm{h}}$ & & & $129^{\mathrm{e}}$ & & 134 & & \\
\hline $\mathrm{Ca}_{0.875} \mathrm{~F}_{0.125} \mathrm{O}$ & 4.686 & 4.691 & 4.822 & 4.827 & & 119.2 & 118.0 & 94.25 & 93.88 & \\
\hline $\mathrm{Ca}_{0.875} \mathrm{Cl}_{0.125} \mathrm{O}$ & 4.727 & 4.729 & 4.855 & 4.857 & & 120.6 & 120.4 & 95.14 & 95.28 & \\
\hline $\mathrm{Ca}_{0.875} \mathrm{Br}_{0.125} \mathrm{O}$ & 4.756 & 4.759 & 4.887 & 4.889 & & 120.0 & 119.9 & 95.71 & 95.73 & \\
\hline $\mathrm{Ca}_{0.875} \mathrm{I}_{0.125} \mathrm{O}$ & 4.810 & 4.814 & 4.941 & 4.943 & & 114,9 & 115.4 & 94.03 & 94.25 & \\
\hline Present & 5.064 & & 5.193 & & $5.160^{\mathrm{i}}$ & 104.4 & & 85.06 & & $91.0^{\mathrm{i}}$ \\
\hline Others & $\begin{array}{l}5.065^{\mathrm{c}} \\
5.072^{\mathrm{h}}\end{array}$ & & $\begin{array}{l}5.196^{\mathrm{c}} \\
5.223^{\mathrm{h}}\end{array}$ & & & $\begin{array}{c}104.1^{\mathrm{c}} \\
0.96^{\mathrm{h}}\end{array}$ & & $\begin{array}{c}86.96^{c} \\
104\end{array}$ & & \\
\hline $\mathrm{Sr}_{0.875} \mathrm{~F}_{0.125} \mathrm{O}$ & 5.022 & 5.029 & 5.165 & 5.173 & & 95.41 & 95.54 & 75.26 & 75.41 & \\
\hline $\mathrm{Sr}_{0.875} \mathrm{Cl}_{0.125} \mathrm{O}$ & 5.046 & 5.051 & 5.188 & 5.193 & & 99.26 & 98.66 & 77.57 & 77.24 & \\
\hline $\mathrm{Sr}_{0.875} \mathrm{Br}_{0.125} \mathrm{O}$ & 5.066 & 5.070 & 5.205 & 5.209 & & 100.0 & 99.55 & 78.38 & 78.28 & \\
\hline $\mathrm{Sr}_{0.875} \mathrm{I}_{0.125} \mathrm{O}$ & 5.105 & 5.109 & 5.243 & 5.246 & & 102.1 & 98.75 & 78.73 & 78.54 & \\
\hline
\end{tabular}

a (Y. Fei, 1999) [13]; b(S. Speziale, 2001) [14]; c [11] (M. Labidi, 2010) [24]; d(M.J. Mehl, 1988) [19]; ' (H.K. Mao, 1979) [20]; ${ }^{\mathrm{f}}($ B.B. Karki, 1998) [21]; g(P. Richet, 1988) [23]; ${ }^{\text {h}}$ F. Marinelli, 2003) [22]; (J.E. Jaffe, 2000) [16].

The relaxed bond length of $\mathrm{AeO}$ host materials and $\mathrm{Ae}_{0.875} \mathrm{M}_{0.125} \mathrm{O}$ are calculated within GGA and LSDA at their equilibrium lattice constant and given in Table 2. From Table 2, it can be seen that, when group VII elements doped at cation site of $\mathrm{AeO}$, the bond length of $\mathrm{M}-\mathrm{O}$ increases as compared to host material. This indicates that the substitution of $\mathrm{F}, \mathrm{Cl}, \mathrm{Br}$ and I for alkaline-earth metal atom would induce a significant local structure distortion. This local structure distortion increases with increasing atomic size of the dopants. Large local structure distortion near the dopant atom has greater impact on electronic structure and thereby reduces the valence band splitting.

"Further to estimate the stability of ferromagnetic state, the spin-polarization energy $\left(\Delta \mathrm{E}=\mathrm{E}_{\mathrm{NM}}-\mathrm{E}_{\mathrm{FM}}\right)$ i.e., the energy gain of the system because of the moments formation is calculated within LSDA and GGA and summarized in Table 2. It is found that ferromagnetic state is energetically stable $(\Delta E>0)$ than nonmagnetic state in all the hosts with group VII elements as dopants, except for I-doped MgO. The ferromagnetic interaction originates from kinetic energy gain of itinerant $p$-electrons of dopant atom. From Table 2, it can be seen that when the size of the dopant atom increases the spin-polarization energy decreases, which means that the ferromagnetic interaction becomes weak. This is because as the size of dopant increases, overlap between the neighboring states increases, resulting in decreasing trend of spin-polarization energy. This suggests that size of dopant atom play a dominant role in determining spin-polarization energy. 
Table 2. Relaxed bond length and total energy difference $(\Delta \mathrm{E})$ between nonmagnetic $(\mathrm{NM})$ and ferromagnetic $(\mathrm{FM})$ states of $\mathrm{Ae}_{0.875} \mathrm{M}_{0.125} \mathrm{O}(\mathrm{Ae}=\mathrm{Mg}$, $\mathrm{Ca}$ and $\mathrm{Sr} ; \mathrm{M}=\mathrm{F}, \mathrm{Cl}, \mathrm{Br}$ and $\mathrm{I})$ using both LSDA and GGA

\begin{tabular}{|c|c|c|c|c|}
\hline \multirow{2}{*}{ Compounds } & \multicolumn{2}{|c|}{ Bond length $(\AA)$} & \multicolumn{2}{c|}{$\Delta \mathrm{E}(\mathrm{ev})$} \\
\cline { 2 - 5 } & LSDA & GGA & LSDA & GGA \\
\hline $\mathrm{MgO}$ & 2.084 & 2.130 & & \\
\hline $\mathrm{Mg}_{0.875} \mathrm{~F}_{0.125} \mathrm{O}$ & 2.096 & 2.146 & 0.3228 & 0.4305 \\
\hline $\mathrm{Mg}_{0.875} \mathrm{Cl}_{0.125} \mathrm{O}$ & 2.140 & 2.188 & 0.0053 & 0.0881 \\
\hline $\mathrm{Mg}_{0.875} \mathrm{Br}_{0.125} \mathrm{O}$ & 2.167 & 2.215 & 0.0010 & 0.0542 \\
\hline $\mathrm{Mg}_{0.875} \mathrm{I}_{0.125} \mathrm{O}$ & 2.212 & 2.262 & 0.0000 & 0.0000 \\
\hline $\mathrm{CaO}$ & 2.359 & 2.419 & & \\
\hline $\mathrm{Ca}_{0.875} \mathrm{~F}_{0.125} \mathrm{O}$ & 2.345 & 2.413 & 0.3710 & 0.5252 \\
\hline $\mathrm{Ca}_{0.875} \mathrm{Cl}_{0.125} \mathrm{O}$ & 2.364 & 2.428 & 0.2966 & 0.4199 \\
\hline $\mathrm{Ca}_{0.875} \mathrm{Br}_{0.125} \mathrm{O}$ & 2.379 & 2.444 & 0.2291 & 0.3822 \\
\hline $\mathrm{Ca}_{0.875} \mathrm{I}_{0.125} \mathrm{O}$ & 2.407 & 2.471 & 0.1232 & 0.2992 \\
\hline $\mathrm{SrO}^{\mathrm{SrO}_{2}}$ & 2.532 & 2.596 & & \\
\hline $\mathrm{Sr}_{0.875} \mathrm{~F}_{0.125} \mathrm{O}$ & 2.514 & 2.586 & 0.3187 & 0.5169 \\
\hline $\mathrm{Sr}_{0.875} \mathrm{Cl}_{0.125} \mathrm{O}$ & 2.525 & 2.596 & 0.2166 & 0.3606 \\
\hline $\mathrm{Sr}_{0.875} \mathrm{Br}_{0.125} \mathrm{O}$ & 2.535 & 2.604 & 0.1829 & 0.3386 \\
\hline $\mathrm{Sr}_{0.875} \mathrm{I}_{0.125} \mathrm{O}$ & 2.554 & 2.623 & 0.1355 & 0.3020 \\
\hline
\end{tabular}

\subsection{Electronic Band Structure and Magnetic Properties}

Alkaline-earth oxides namely $\mathrm{MgO}, \mathrm{CaO}$ and $\mathrm{SrO}$ have the same rocksalt $(\mathrm{NaCl})$ crystal structure. The electronic band structure of the host $\mathrm{AeO}$ compounds are calculated within GGA and LSDA, however the band structure calculated within GGA are presented in Figure 1. The overall band structure profile is same for all the AeO hosts and similar to that of other wide bandgap semiconductors. Also there is no significant difference observed within the AeO band structures obtained by LSDA and GGA. Basically, the bands can be classified by the atomic levels they originate from. The uppermost valence band mainly originates from $2 p$-like states of $\mathrm{O}$ and the low-lying band comes from $2 s$-like state of $\mathrm{O}$. Additionally, $\mathrm{Sr}$ semicore $p$-like bands occur close in energy to the O $2 s$ band. The lowest unoccupied conduction band originates in all three oxides from $s$ - and $d$-like states of alkaline-earth atom. The valence band maximum occurs at $\Gamma$ point in all $\mathrm{AeO}$ and the conduction band minimum occurs at $\Gamma$ point in $\mathrm{MgO}$ while it occurs at $\mathrm{X}$ in the other two oxides. As a consequence, the gap is direct at $\Gamma$ in $\mathrm{MgO}$ while it is indirect from $\Gamma$ to $\mathrm{X}$ in $\mathrm{CaO}$ and $\mathrm{SrO}$."

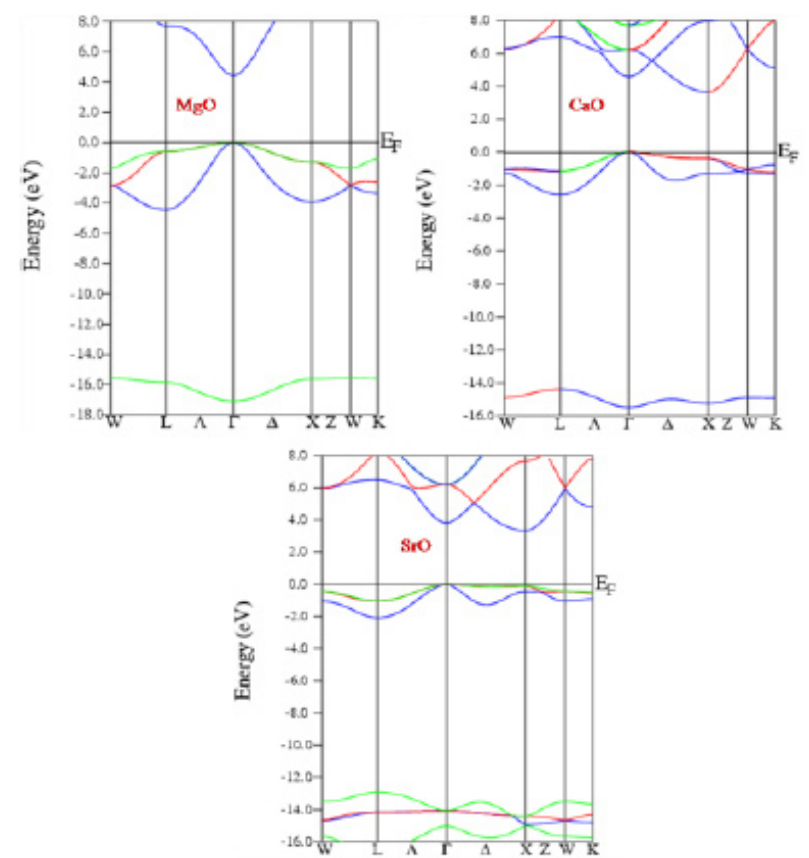

Figure 1. The electronic band structures of $\mathrm{MgO}, \mathrm{CaO}$ and SrO compounds within GGA.

The spin-resolved electronic band structures of $\mathrm{Ae}_{0.875} \mathrm{M}_{0.125} \mathrm{O}$ at their equilibrium lattice constant have been calculated along high symmetry directions within LSDA and GGA, for illustration, the band structure of $\mathrm{Ca}_{0.875} \mathrm{M}_{0.125} \mathrm{O}$ is shown in Figures 2-6. The electronic band structure profiles are same for all the doped compounds. The substitution of group VII elements for alkaline-earth metal atom in AeO favors the spin-polarized state in alkaline-earth oxides. This can be seen in the electronic band structures (Figure 2-6) which show spin-splitting between the majority spin state and minority spin state around the Fermi level. It suggests that, within both LSDA and GGA addition of group VII elements can order magnetism in $\mathrm{AeO}$ host, except for I-doped $\mathrm{MgO}$. Hence these binary host compounds are no longer nonmagnetic insulators.

Within GGA calculation, it has been observed that in $\mathrm{AeO}$ host, $\mathrm{F}$ alone induces $\mathrm{HM}$ in $\mathrm{MgO}$ host, whereas in $\mathrm{CaO}$ and $\mathrm{SrO}$ host all the group VII elements induce half-metallicity with one spin channel exhibiting semiconducting behavior and another spin channel exhibiting semimetallic behavior. This kind of peculiar band structure is the distinctive property of HM ferromagnets, hence these compounds exhibit HM ferromagnetic property. Here $\mathrm{Cl}, \mathrm{Br}$ and I-doped systems exhibit semimetallic property in majority spin state, whereas semiconducting 

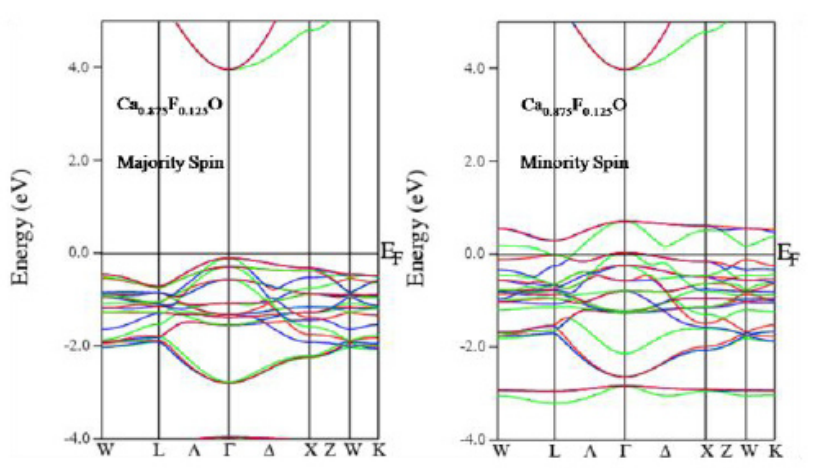

Figure 2. Spin-resolved electronic band structure of F-doped $\mathrm{CaO}$ within LSDA.
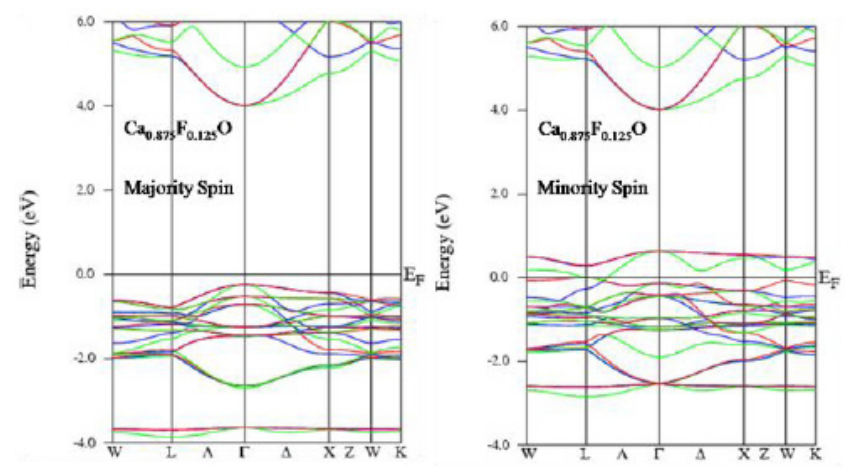

Figure 3. Spin-resolved electronic band structure of F-doped $\mathrm{CaO}$ within GGA.
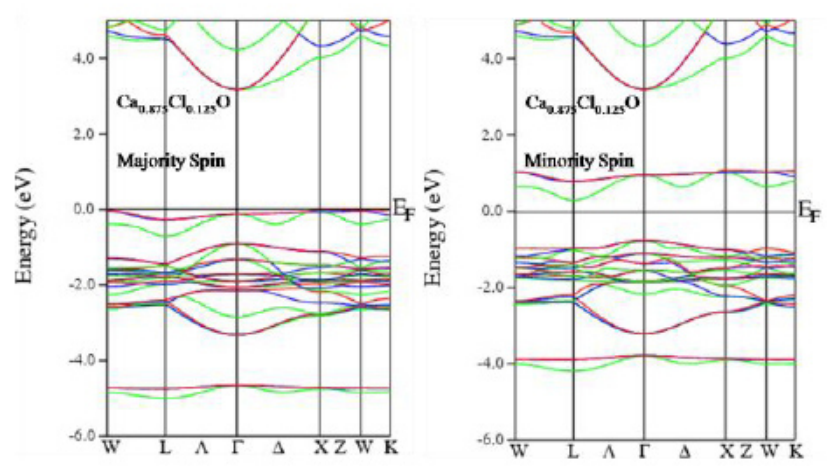

Figure 4. Spin-resolved electronic band structure of Cldoped $\mathrm{CaO}$ within GGA.

property in minority spin state and it is reverse in the case of F-doped AeO. The calculations within LSDA reveals that half-metallic property is observed in the case of $\mathrm{CaO}$ and $\mathrm{SrO}$ doped with group VII elements, except for I-doped $\mathrm{CaO}$, but in the case of $\mathrm{MgO}$ host, half-metallicity is not induced by group VII elements.
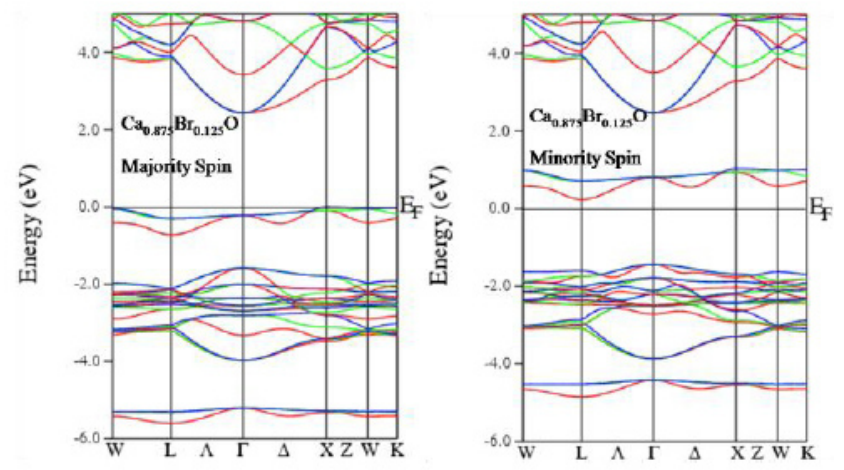

Figure 5. Spin-resolved electronic band structure of Br-doped $\mathrm{CaO}$ within GGA.
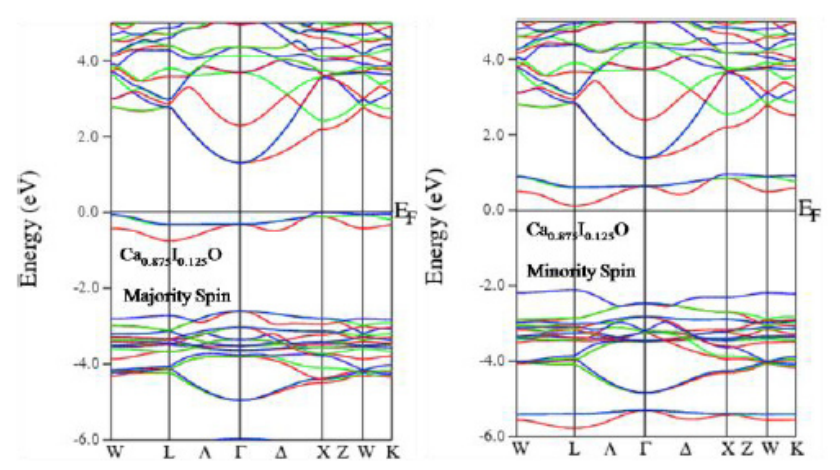

Figure 6. Spin-resolved electronic band structure of I-doped $\mathrm{CaO}$ within GGA.

The total and partial magnetic moments of $\mathrm{Ae}_{0.875} \mathrm{M}_{0.125} \mathrm{O}$ are obtained using LSDA and GGA and are summarized in Tables 3 and 4. From Tables 3 and 4 , it is found that doping with $\mathrm{F}$ alone induce HM ferromagnetism in $\mathrm{MgO}$ host within GGA-PBE, others $(\mathrm{Cl}$, $\mathrm{Br}$ and I) does not exhibit HM ferromagnetism within both LSDA and GGA. However interestingly $\mathrm{CaO}$ and SrO hosts doped with group VII elements (F, Cl, Br and I) exhibit HM ferromagnetism with a total integer magnetic moment of $3.00 \mu_{\mathrm{B}} /$ cell within GGA. Whereas calculation within LSDA indicates that all dopants induce half-metallicity in $\mathrm{CaO}$ and $\mathrm{SrO}$ host, except for I-doped $\mathrm{CaO}$. An integer value of the total magnetic moment is a significant feature of HM ferromagnets. The spin-polarized calculations clearly show that the contribution to total magnetic moment primarily comes from $\mathrm{O}$ atom. In all these doped systems, the magnetic moments are oriented in the same direction, indicating ferromagnetic coupling between the dopant ( $\mathrm{F}, \mathrm{Cl}, \mathrm{Br}$ and $\mathrm{I}$ ) and neighboring host atoms. The magnetic moment of $\mathrm{O}$ decreases with 
increasing atomic size of the dopant. From Tables 3 and 4 , it is found that the total and partial magnetic moments calculated within GGA are different from LSDA, this is because LSDA delocalizes the electrons more when compared to GGA, indicating LSDA scheme underestimates the magnetic moment.

The HM gap is defined as the minimum energy gap between the highest energy of majority spin valence band and the Fermi level. The HM gap is calculated and given in Table 5. The nonzero values of the HM gaps for these compounds illustrate them to be true half-metallic ferromagnets. However, the HM gap decreases with increasing size of the dopant atom from $\mathrm{Cl}$ to $\mathrm{Br}$. When the size of the dopant is increased, it is found that the impurity energy bands tend to broaden more strongly and delocalize the electrons more hence it substantially decreases the spinsplitting thereby reducing the HM gap.

\subsection{Density of States and Origin of Ferromagnetism}

Figures 7 and 8 show the calculated total density of states (DOS) and partial density of states (PDOS) of $\mathrm{Ca}_{0.875} \mathrm{M}_{0.125} \mathrm{O}$. It shows that, the dopants change the DOS

Table 3. Total and partial magnetic moments of $\mathrm{Ae} 0.875 \mathrm{M} 0.125 \mathrm{O}(\mathrm{Ae}=\mathrm{Mg}, \mathrm{Ca}$ and $\mathrm{Sr} ; \mathrm{M}=\mathrm{F}, \mathrm{Cl}, \mathrm{Br}$ and I) compounds at their equilibrium lattice constant within LSDA

\begin{tabular}{|c|c|c|c|c|c|}
\hline \multirow{2}{*}{ Compounds } & \multicolumn{5}{|c|}{ Magnetic moment $\left(\mu_{\mathrm{B}}\right)$} \\
\cline { 2 - 6 } & $\mathrm{Ae}$ & $\mathrm{O}$ & Dopant & Interstitial & Total \\
\hline $\mathrm{MgO}$ & & & & & \\
\hline $\mathrm{Mg}_{0.875} \mathrm{~F}_{0.125} \mathrm{O}$ & 0.019 & 1.969 & 0.933 & 0.064 & 2.985 \\
\hline $\mathrm{Mg}_{0.875} \mathrm{Cl}_{0.125} \mathrm{O}$ & 0.010 & 0.572 & 0.484 & 0.103 & 1.169 \\
\hline $\mathrm{Mg}_{0.875} \mathrm{Br}_{0.125} \mathrm{O}$ & 0.000 & 0.002 & 0.002 & 0.001 & 0.005 \\
\hline $\mathrm{Mg}_{0.875} \mathrm{I}_{0.125} \mathrm{O}$ & 0 & 0 & 0 & 0 & 0 \\
\hline $\mathrm{CaO}$ & & & & & \\
\hline $\mathrm{Ca}_{0.875} \mathrm{~F}_{0.125} \mathrm{O}$ & 0.015 & 2.071 & 0.818 & 0.096 & 3.00 \\
\hline $\mathrm{Ca}_{0.875} \mathrm{Cl}_{0.125} \mathrm{O}$ & 0.024 & 1.636 & 1.064 & 0.276 & 3.00 \\
\hline $\mathrm{Ca}_{0.875} \mathrm{Br}_{0.125} \mathrm{O}$ & 0.025 & 1.527 & 1.157 & 0.291 & 3.00 \\
\hline $\mathrm{Ca}_{0.875} \mathrm{I}_{0.125} \mathrm{O}$ & 0.038 & 1.361 & 1.070 & 0.483 & 2.952 \\
\hline $\mathrm{SrO}^{2} \mathrm{O}$ & & & & & \\
\hline $\mathrm{Sr}_{0.875} \mathrm{~F}_{0.125} \mathrm{O}$ & 0.021 & 2.163 & 0.717 & 0.099 & 3.00 \\
\hline $\mathrm{Sr}_{0.875} \mathrm{Cl}_{0.125} \mathrm{O}$ & 0.026 & 1.796 & 0.926 & 0.252 & 3.00 \\
\hline $\mathrm{Sr}_{0.875} \mathrm{Br}_{0.125} \mathrm{O}$ & 0.024 & 1.680 & 1.037 & 0.259 & 3.00 \\
\hline $\mathrm{Sr}_{0.875} \mathrm{I}_{0.125} \mathrm{O}$ & 0.027 & 1.520 & 1.026 & 0.427 & 3.00 \\
\hline
\end{tabular}

Table 4. Total and partial magnetic moments of Ae0.875M0.125O ( $\mathrm{Ae}=\mathrm{Mg}$, $\mathrm{Ca}$ and $\mathrm{Sr} ; \mathrm{M}=\mathrm{F}, \mathrm{Cl}, \mathrm{Br}$ and I) compounds at their equilibrium lattice constant within GGA

\begin{tabular}{|c|c|c|c|c|c|}
\hline \multirow{2}{*}{ Compounds } & \multicolumn{5}{|c|}{ Magnetic moment $\left(\mu_{\mathrm{B}}\right)$} \\
\cline { 2 - 6 } & $\mathrm{Ae}$ & $\mathrm{O}$ & Dopant & Interstitial & Total \\
\hline $\mathrm{MgO}$ & & & & & \\
\hline $\mathrm{Mg}_{0.875} \mathrm{~F}_{0.125} \mathrm{O}$ & 0.012 & 2.032 & 0.902 & 0.054 & 3.00 \\
\hline $\mathrm{Mg}_{0.875} \mathrm{Cl}_{0.125} \mathrm{O}$ & 0.029 & 1.369 & 1.116 & 0.265 & 2.779 \\
\hline $\mathrm{Mg}_{0.875} \mathrm{Br}_{0.125} \mathrm{O}$ & 0.006 & 0.427 & 0.354 & 0.125 & 0.912 \\
\hline $\mathrm{Mg}_{0.875} \mathrm{I}_{0.125} \mathrm{O}$ & 0 & 0 & 0 & 0 & 0 \\
\hline $\mathrm{CaO} \mathrm{O}$ & & & & & \\
\hline $\mathrm{Ca}_{0.875} \mathrm{~F}_{0.125} \mathrm{O}$ & 0.007 & 1.952 & 0.753 & 0.288 & 3.00 \\
\hline $\mathrm{Ca}_{0.875} \mathrm{Cl}_{0.125} \mathrm{O}$ & 0.020 & 1.588 & 1.008 & 0.384 & 3.00 \\
\hline $\mathrm{Ca}_{0.875} \mathrm{Br}_{0.125} \mathrm{O}$ & 0.022 & 1.467 & 1.129 & 0.382 & 3.00 \\
\hline $\mathrm{Ca}_{0.875} \mathrm{I}_{0.125} \mathrm{O}$ & 0.032 & 1.307 & 1.095 & 0.566 & 3.00 \\
\hline $\mathrm{SrO} \mathrm{Sr}$ & & & & & \\
\hline $\mathrm{Sr}_{0.875} \mathrm{~F}_{0.125} \mathrm{O}$ & 0.008 & 2.212 & 0.673 & 0.107 & 3.00 \\
\hline $\mathrm{Sr}_{0.875} \mathrm{Cl}_{0.125} \mathrm{O}$ & 0.019 & 1.864 & 0.864 & 0.253 & 3.00 \\
\hline $\mathrm{Sr}_{0.875} \mathrm{Br}_{0.125} \mathrm{O}$ & 0.019 & 1.724 & 0.999 & 0.258 & 3.00 \\
\hline $\mathrm{Sr}_{0.875} \mathrm{I}_{0.125} \mathrm{O}$ & 0.023 & 1.533 & 0.953 & 0.491 & 3.00 \\
\hline
\end{tabular}

Table 5. Calculated half-metallic (HM) gap and exchange splitting energy $(\Delta x)$ of Ae0.875M0.125O $(\mathrm{Ae}=\mathrm{Mg}$, Ca and $\mathrm{Sr} ; \mathrm{M}=\mathrm{F}, \mathrm{Cl}, \mathrm{Br}$ and $\mathrm{I})$ using both LSDA and GGA

\begin{tabular}{|c|c|c|c|c|}
\hline \multirow{2}{*}{ Compounds } & \multicolumn{2}{|c|}{ HM gap (ev) } & \multicolumn{2}{c|}{$\Delta \mathbf{x}(\mathrm{ev})$} \\
\cline { 2 - 5 } & LSDA & GGA & LSDA & GGA \\
\hline $\mathrm{MgO}$ & & & & \\
\hline $\mathrm{Mg}_{0.875} \mathrm{~F}_{0.125} \mathrm{O}$ & - & 0.166 & 0.439 & 0.498 \\
\hline $\mathrm{Mg}_{0.875} \mathrm{Cl}_{0.125} \mathrm{O}$ & - & - & 0.402 & 1.068 \\
\hline $\mathrm{Mg}_{0.875} \mathrm{Br}_{0.125} \mathrm{O}$ & - & - & 0.002 & 0.314 \\
\hline $\mathrm{Mg}_{0.875} \mathrm{I}_{0.125} \mathrm{O}$ & - & - & - & - \\
\hline $\mathrm{CaO}$ & & & & \\
\hline $\mathrm{Ca}_{0.875} \mathrm{~F}_{0.125} \mathrm{O}$ & 0.107 & 0.241 & 0.721 & 0.745 \\
\hline $\mathrm{Ca}_{0.875} \mathrm{Cl}_{0.125} \mathrm{O}$ & 0.140 & 0.284 & 0.907 & 0.997 \\
\hline $\mathrm{Ca}_{0.875} \mathrm{Br}_{0.125} \mathrm{O}$ & 0.032 & 0.230 & 0.813 & 0.958 \\
\hline $\mathrm{Ca}_{0.875} \mathrm{I}_{0.125} \mathrm{O}$ & - & 0.114 & 0.662 & 0.869 \\
\hline $\mathrm{SrO}^{\mathrm{Sr}_{y y y y}}$ & & & & \\
\hline $\mathrm{Sr}_{0.875} \mathrm{~F}_{0.125} \mathrm{O}$ & 0.006 & 0.166 & 0.658 & 0.694 \\
\hline $\mathrm{Sr}_{0.875} \mathrm{Cl}_{0.125} \mathrm{O}$ & 0.182 & 0.342 & 0.809 & 0.889 \\
\hline $\mathrm{Sr}_{0.875} \mathrm{Br}_{0.125} \mathrm{O}$ & 0.144 & 0.314 & 0.751 & 0.870 \\
\hline $\mathrm{Sr}_{0.875} \mathrm{I}_{0.125} \mathrm{O}$ & 0.053 & 0.257 & 0.048 & 0.820 \\
\hline
\end{tabular}


significantly near the Fermi level. It leads to the spinpolarization of valence band but it does not affect the conduction band. This asymmetrical distribution of DOS is observed between the spin-up and spin-down states in all the doped systems, except for I-doped MgO. This means that ferromagnetism is induced in all doped systems but not in the case of I-doped MgO. From the total DOS (Figs. 7 and 8 (left side)), it is found that the majority spin state of $\mathrm{CaO}$ doped with $\mathrm{Cl}, \mathrm{Br}$ and I exhibit semimetallic behavior, whereas minority spin state exhibit semiconducting behavior, and reverse in F-doped AeO, same trend is observed in $\mathrm{SrO}$.

Hence it confirms that these compounds are true HM ferromagnets. However group VII elements do not induce half-metallicity in $\mathrm{MgO}$ host within LSDA, whereas within GGA, F-alone induces $\mathrm{HM}$ property in $\mathrm{MgO}$. Here HM ferromagnetism is formed due to the spontaneous spin-polarization of $2 p$ and $n p$ bands of oxygen and dopant atoms. In this case ferromagnetism arises due to exchange splitting of the $p$ bands of both anion and dopant atoms. The exchange splitting energy $(\Delta x)$ is defined as the average energy difference between majority and minority spin bands. From Table 5, the exchange splitting energy decreases as the size of the dopant increases from $\mathrm{Cl}$ to I and this reduction in spin-splitting leads to the loss of half-metallic behavior. In $\mathrm{MgO}$ the overlapping of the wave function of the dopant $\mathrm{n} p$ like states with oxygen $p$-like states is more; this reduces the magnetic moment in these systems when compared to $\mathrm{CaO}$ and $\mathrm{SrO}$.

The PDOS are calculated to understand the spin-polarization in these systems. The states near the Fermi level (Figures 7 and 8) mainly originate from $n p$-like states of dopant and $2 p$-like states of oxygen, and strong hybridization between these two states are also clearly observed. Replacement of alkaline-earth metal by partially filled valence $p$ shell elements introduces holes into the valence band. These spin-polarized holes mediate the ferromagnetic coupling, through strong interaction between $n p$ like states of dopants and $2 p$-like states of oxygen (Yogeswari, 2013) [27].

The $p$ - $d$ exchange like $p-p$ coupling involving holes is responsible for the observed magnetic coupling in the present system. Here the nonmagnetic dopant hybridizes strongly with its neighboring anions of the AeO host and then the neighboring anions are spin-polarized with large magnetization and couple ferromagnetically, resulting in an indirect FM coupling among dopants. At the same time, it is possible that $p$ - $d$ exchange like $p-p$ interaction
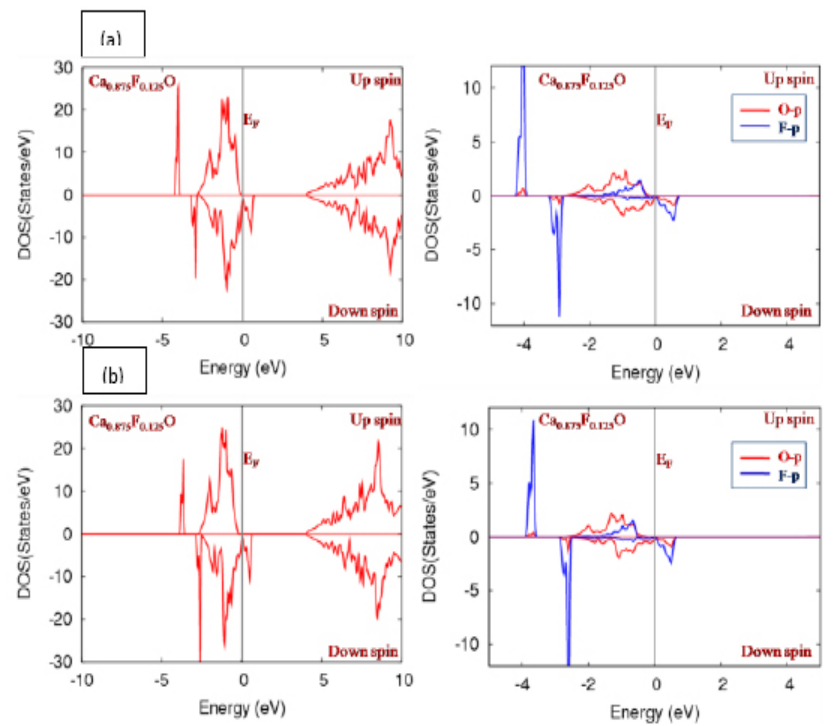

Figure 7. Spin-resolved total and partial density of states of Ca0.875F0.125O at its equilibrium volume within. (a) LSDA. (b) GGA.
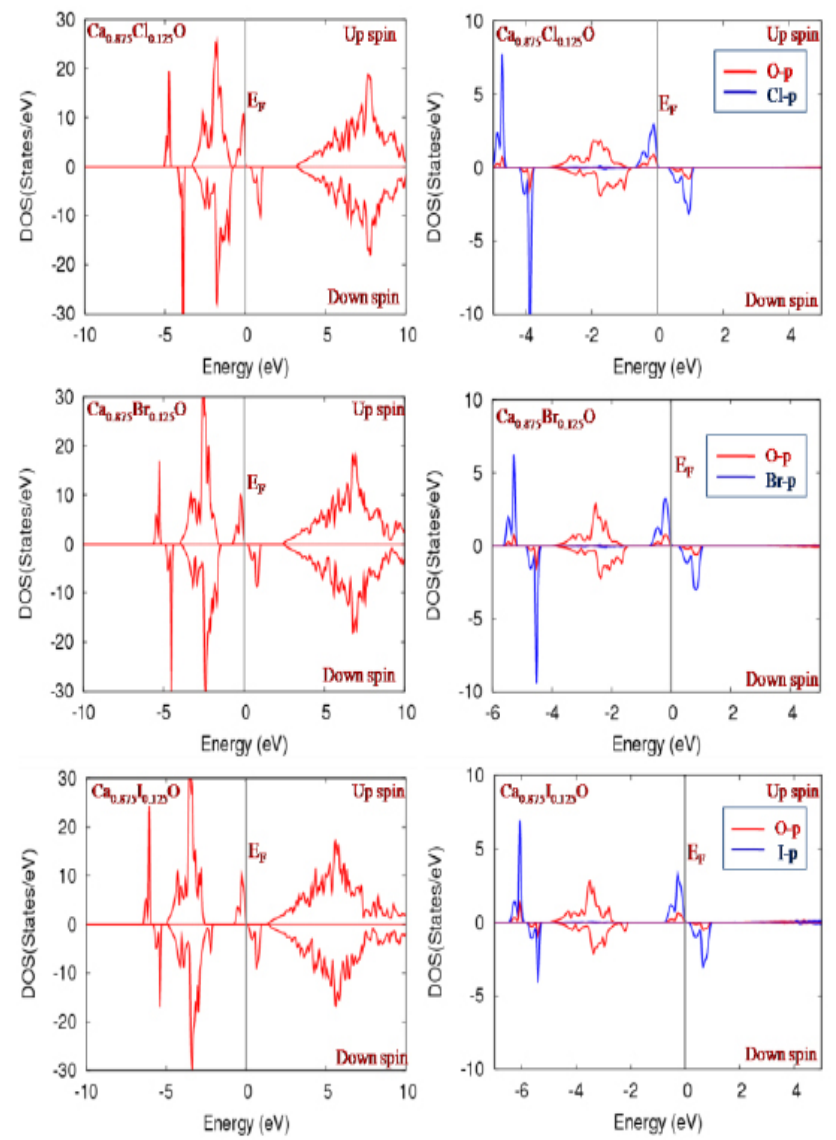

Figure 8. Spin-resolved total and partial density of states of $\mathrm{Ca} 0.875 \mathrm{M} 0.125 \mathrm{O}(\mathrm{M}=\mathrm{Cl}, \mathrm{Br}$ and $\mathrm{I})$ at their equilibrium volume. 
is responsible for the observed magnetic coupling similar to C, N-doped ZnS (R. Long, 2009) [18]. As a result of strong $p$ - $p$ interaction, splitting of energy levels occur around the Fermi energy.

\section{Conclusion}

To conclude, the detailed electronic and magnetic properties of $\mathrm{Ae}_{0.875} \mathrm{M}_{0.125} \mathrm{O}$ have been studied on the basis of DFT calculations. Total energy calculations show that at equilibrium condition these compounds are stable in the ferromagnetic state when compared to nonmagnetic state, except for I-doped MgO. The results of the electronic band structure and DOS calculation revealed that the substitution of $\mathrm{F}, \mathrm{Cl}, \mathrm{Br}$, and I for alkaline-earth metal in the AeO leads to spontaneous spin-polarization of the valence states of dopant which make the doped material magnetic. It is found that the $\mathrm{Ae}_{0.875} \mathrm{M}_{0.125} \mathrm{O}$ compounds represent HM ferromagnetism with spin-dependent transport properties, in which the conduction proceeds entirely via the minority spin state in $\mathrm{F}$-doped $\mathrm{AeO}$ and through majority spin state in $\mathrm{Cl}, \mathrm{Br}$ and $\mathrm{I}$-doped $\mathrm{CaO}$ and $\mathrm{SrO}$. The calculated total magnetic moment is $3.00 \mu_{\mathrm{B}} /$ cell. There is no significant difference observed in ground state properties while using LSDA and GGA functional. But considerable difference is observed in magnetic properties. These compounds can be of interest as spin-injectors in spintronic devices.

\section{References}

1. de Groot RA, Mueller FM, van Engen PG, Buschow KHJ. New class of materials: Half-metallic ferromagnets, Phys Rev Lett. 1983; 50:2024-7. Available from: https://doi. org/10.1103/PhysRevLett.50.2024

2. Zhao YH, Xie WH, Zhu LF, Liu BG. Half-metallic ferromagnets based on the rock-saltIV-VIsemiconductor GeTe, Journal of Physics: Condensed Matter. 2006; 18:10259. Available from: https://doi.org/10.1088/0953-8984/18/45/012

3. Kenmochi K, Seike M, Sato K, Yanase A, Katayama YH. New class of diluted ferromagnetic semiconductors based on $\mathrm{CaO}$ without transition metal elements. Jpn J Appl Phys. 2004; 43:L934-6. Available from: https://doi.org/10.1143/ JJAP.43.L934

4. Kenmochi K, Dinh VA, Sato K, Yanase A, Katayama-Yoshida H. Materials design of transparent and half-metallic ferromagnets of $\mathrm{MgO}, \mathrm{SrO}$ and $\mathrm{BaO}$ without magnetic elements. J Phys Soc Jpn. 2004; 73:2952-4. Available from: https://doi. org/10.1143/JPSJ.73.2952
5. Shein IR, Ryzhkov MV, Gorbunova MA, Makurin YN, Ivanovskii AL. Magnetization of beryllium oxide in the presence of nonmagnetic impurities: Boron, carbon, and nitrogen. JETP Lett. 2007; 85:246-50. Available from: https://doi.org/10.1134/S0021364007050062

6. Liu J, Chen L, Dong HN, Zheng RL. First-principle study on the magnetic properties of six potential half-metallic ferromagnets: C-doped alkaline-earth chalcogenides. Appl Phys Lett. 2009; 95132502. Available from: https://doi. org/10.1063/1.3242013

7. Blaha P, Schwarz K, Sorantin P, Trickey SB. Fullpotential, linearized augmented plane wave programs for crystalline systems. Comput Phys Commun. 1990; 59399-415. Available from: https://doi.org/10.1016/00104655(90)90187-6

8. Ceperley DM, Alder BJ. Ground state of the electron gas by a stochastic method. Phys Rev Lett. 1980; 45566-9. Available from: https://doi.org/10.1103/PhysRevLett.45.566

9. Perdew JP, Burke K, Ernzerhof M. Generalized gradient approximation made simple. Phys Rev Lett. 1996; 77:3865-8. PMid:10062328: Available from: https://doi. org/10.1103/PhysRevLett.77.3865

10. Koelling DD, Harmon BN. A technique for relativistic spinpolarised calculations. J Phys C: Solid State Phys. 1977; 10:3107-14. Available from: https://doi.org/10.1088/0022$3719 / 10 / 16 / 019$

11. Blöchl PE, Jepsen O, Andersen OK. Improved tetrahedron method for Brillouin-zone integrations. Phys Rev B. 1994; 49:16223-33. Available from: https://doi.org/10.1103/ PhysRevB.49.16223

12. Yogeswari M, Umamaheswari R, Kalpana G. First principles study of electronic and magnetic properties of AeS0.875X0.125 ( $\mathrm{Ae}=\mathrm{Mg}, \mathrm{Ca}$ and Sr; X = N, P, As and Sb). Computational Materials Science. 2012; 54:219-26. Available from: https://doi.org/10.1016/j. commatsci.2011.11.008

13. Fei Y. Effects of temperature and composition on the bulk modulus of (Mg,Fe)O. Amer Mineral. 1999; 84:272-6. Available from: https://doi.org/10.2138/am-1999-0308

14. Speziale S, Zha CS, Duffy TS, Hemley RJ, Mao HK. Quasi-hydrostatic compression of magnesium oxide to $52 \mathrm{GPa}$ - Implications for the pressure-volume-temperature equation of state. J Geophys Res. 2001; 106:515-28. Available from: https://doi.org/10.1029/2000JB900318

15. Tsuchiya T, Kawamura K. Systematics of elasticity: Ab initio study in B1-type alkaline earth oxides. J Chem Phys. 2001; 114:10086-93. Available from: https://doi. org/10.1063/1.1371498

16. Jaffe JE, Snyder JA, Lin Z, Hess AC. LDA and GGA calculations for high-pressure phase transitions in $\mathrm{ZnO}$ and $\mathrm{MgO}$. Phys Rev B. 2000; 62:1660-5. Available from: https://doi. org/10.1103/PhysRevB.62.1660 
17. Birch F. Finite elastic strain of cubic crystals. Phys Rev B. 1947; 71:809-24. Available from: https://doi.org/10.1103/ PhysRev.71.809

18. Long R, English NJ. Magnetic properties of first-row element-doped ZnS semiconductors: A density functional theory investigation. Phys Rev B. 2009; 80:115212. Available from: https://doi.org/10.1103/PhysRevB.80.115212

19. Mehl MJ, Cohen RE, Krakauer H. Linearized augmented plane wave electronic structure calculations for $\mathrm{MgO}$ and CaO. J Geophys Res. 1988; 93:8009-22. Available from: https://doi.org/10.1029/JB093iB07p08009

20. Mao HK, Bell PM. Equations of state of $\mathrm{MgO}$ and $\varepsilon$ Fe under static pressure conditions. J Geophys Res. 1979; 84:4533-6. Available from: https://doi.org/10.1029/JB084iB09p04533

21. Karki BB, Crain J. Structure and elasticity of $\mathrm{CaO}$ at high pressure. J Geophys Res. 1998; 103:12405-12. Available from: https://doi.org/10.1029/97JB03674

22. Marinelli F, Lichanot A. Elastic constants and electronic structure of alkaline-earth chalcogenides. Performances of various Hamiltonians. Chem Phys Lett. 2003; 367:430-8. Available from: https://doi.org/10.1016/S00092614(02)01698-6
23. Richet P, Mao HK, Bell PM. Static compression and equation of state of $\mathrm{CaO}$ to 1.35 Mbar. J Geophys Res. 1988; 93:15279-88. Available from: https://doi.org/10.1029/ JB093iB12p15279

24. Labidi M, Labidi S, Ghemid S, Meradji H, Hassan FEH. Structural, electronic, thermodynamic and optical properties of alkaline earth oxides $\mathrm{MgO}, \mathrm{SrO}$ and their alloys. Phys Scr. 2010; 82:045605. Available from: https://doi. org/10.1088/0031-8949/82/04/045605

25. Ethiraj RD, Kalpana G. Magnetism induced by nonmagnetic dopant in Li2O, Na2O, K2O and Rb2O: first-principles calculations. Journal of Materials Science. 2012; 47:2316-21. Available from: https://doi.org/10.1007/s10853-011-6046-y

26. Yogeswari M, Kalpana G. Electronic structure and halfmetallic ferromagnetism in $(\mathrm{C}, \mathrm{Si}, \mathrm{Ge}$ and $\mathrm{Sn})$ doped alkaline-earth sulfides: A first principles approach. Journal of Alloys and Compounds. 20131; 573:83-9. Available from: https://doi.org/10.1016/j.jallcom.2013.03.275

27. Yogeswari M, Umamaheswari R, Kalpana G. Half-metallic ferromagnetism in MgS by doping with Sp-element: A first-principles calculations. Advanced Materials Research. Trans Tech Publications. 2013; 665: 22-8. 